\title{
Storm Fronts AND Filmmaking: Cloud CoMPuting Regulation AND THE IMPACT ON INDEPENDENT FILMMAKERS
}

\author{
By Gregory Graham* \\ Volume XIII - Fall 2012
}

The rise of cloud computing has begun to transform media technology and wider industries. No longer constrained by the relative size of their server network or budget limitations, businesses are taking advantage of cloud computing's promise to access previously unimaginable computing resources. ${ }^{1}$ The film industry in particular has taken advantage of the increased capabilities offered by cloud computing. ${ }^{2}$ This recognition has begun a transformation that has spread from major Hollywood studios to smaller independent production companies. ${ }^{3}$ Major studios are turning to cloud providers for the creation of Computer Generated Image (CGI) blockbusters, while independent filmmakers are taking advantage of cloud computing's low costs to create and distribute their films. ${ }^{4}$ This resulting "democratization of the film industry" has resulted in a trend towards more independent films being released since $2002 .^{5}$

\footnotetext{
* Gregory Graham, University of Pittsburgh School of Law, J.D. Candidate, May 2013.

${ }^{1}$ A Microsoft survey of small business owners found that $54 \%$ of those surveyed identified lower costs as the principal benefit of a switch to cloud computing. $47 \%$ found that they would likely be more productive, and $30 \%$ identified the capacity to innovate as the chief benefit. $78 \%$ were found to be either current cloud users or "nextwave" movers. Drivers \& Inhibitors to Cloud Adoption for Small and Midsize Businesses, Microsoft Corp., http://www.microsoft.com/en-us/news/presskits/telecom/docs/SMBCloud.pdf (last visited Nov. 18, 2012) [hereinafter Edge Strategies].

${ }^{2}$ Jeff Steele, Power to the People: The Democratization of Film, FiLmCLOSINGs.COM, http://filmclosings.com/2011/02/power-to-the-people-the-democratization-of-film/ (last visited Oct. 15, 2012).

${ }^{3}$ Id.; George Avgerakis, Ahead in the Cloud, HDVIDEOPRO.COM (Sept. 20, 2011), http://www.hdvideopro.com/technology/miscellaneous-technology/ahead-in-thecloud.html? start=2.

${ }^{4}$ Steele, supra note 2; Avgerakis, supra note 3.

${ }^{5}$ Indie Films On the Rise But Releases Often Smaller, Brick Top Productions (May 25, 2012), http://bricktopproductions.com/2012/05/25/indie-films-on-the-rise-but-releases-are-often-smaller/.
} 
Hand-in-hand with promises of increased computing ability comes legal uncertainty due to the nature of the service. ${ }^{6}$ As uncertainty regarding the usage of the medium remains, cloud computing's potential is arguably limited. Independent filmmakers are unlikely to fully embrace the cloud unless they are sure that their data and created content is safe. ${ }^{7}$ Unfortunately, information shared and distributed through the Internet has been subject to recent scrutiny regarding copyright-infringement. ${ }^{8}$ Although failing due to vehement opposition, the recent Stop Online Privacy Act (SOPA) contained provisions to combat copyright infringement that were so broad that the providers of cloud services were unsure how to proceed with the provision of services under such regulation. ${ }^{9}$

While a second attempt to pass the legislation was feared, this was laid to rest in October 2012, as SOPA was officially announced as dead and buried. ${ }^{10}$ Although handed a reprieve, the uncertainty surrounding the continued the use of cloud computing by independent filmmakers remains. The desire to regulate the content that is uploaded and accessed across the Internet and particular clouds is based on monetary interests held by an extremely powerful lobbying group. ${ }^{11}$ Furthermore, policies that reflect provisions found within SOPA are already being negotiated

\footnotetext{
${ }^{6}$ Forward Foods, LLC v. Next Proteins, Inc., 873 N.Y.S.2d 511 (N.Y. Sup. Ct. 2008) (analyzed the usage of a virtual storage room for the acquisition of a target company in a sale); Arista Records, LLC v. Usenet.com, Inc., 633 F. Supp. 2d 124 (S.D.N.Y. 2009) (copyright infringement action); Columbia Pictures, Inc. v. Bunnell, 245 F.R.D. 443 (C.D. Cal. 2007) (E-Discovery compelled when defendant moved data from one server to another a month before trial).

${ }^{7}$ David Linthicum, How SOPA Threatens the Move to the Cloud, INFOWORLD.COM (Jan. 4, 2012), http://www.infoworld.com/d/cloud-computing/how-sopa-threatens-the-move-the-cloud-183050 (discussing potential effects on relationship between cloud provider and client that SOPA would have created).

${ }^{8}$ David Sohn \& Andrew McDiarmid, Dangerous Bill Would Threaten Legitimate Websites, ThE ATLANTIC, Nov. 17, 2011, http://www.theatlantic.com/technology/archive/2011/11/dangerous-bill-would-threaten-legitimatewebsites/248619/.

${ }^{9}$ Linthicum, supra note 7.

${ }^{10}$ Joe Mullin, MPAA Chief Admits: SOPA and PIPA “are dead, they're not coming back.', ARSTECHNICA.COM (Oct. 3, 2012), http://arstechnica.com/tech-policy/2012/10/mpaa-chief-admits-sopa-and-pipa-are-dead-theyre-not-comingback/.

${ }^{11}$ See generally, Jolie O'Dell, Here's What Hollywood And Silicon Valley Are spending On SOPA, VENTUREBEAT (Dec. 19, 2011), http://venturebeat.com/2011/12/19/sopa-lobbying/; Tom Cheredar, Official List of SOPA Supporters Includes the X-Men, Bible Publishers \& Country Music, VentureBEAT (Dec. 22, 2011), http://venturebeat.com/2011/12/22/list-of-sopa-supporters/.
} 
directly between bill proponents and the cloud service providers themselves. ${ }^{12}$ As this motivation remains, attempts to regulate and control the content through legislation continue to pose a constant threat to the development of cloud computing as a medium. Accordingly, independent filmmakers who have come to rely on cloud computing to create, store, and distribute their productions cannot fully embrace the potential services. This Note argues that the threat of this overly broad regulation obstructs the development of cloud computing as a medium for independent productions. Part I of this Note introduces cloud computing. Part II focuses on why cloud computing has become so useful to independent filmmakers. Finally, Part III argues that broad regulatory efforts, similar to SOPA, remain as threats to the growth of the medium.

\section{PART I: An Introduction to Cloud Computing}

Modern businesses rely on business applications to increase efficiency. ${ }^{13}$ That efficiency comes at a cost, as all computer-based networks require a data center with the requisite space for servers and network capacity. ${ }^{14}$ This data center requires servers, networks, and a network staff to maintain and update it efficiently. ${ }^{15}$ Logically, as a business grows, the financial costs

\footnotetext{
${ }^{12}$ Nate Anderson, Major ISPs Agree to "Six Strikes" Copyright Enforcement Plan, ARSETECHNICA.COM, (July 7, 2011), http://arstechnica.com/tech-policy/2011/07/major-isps-agree-to-six-strikes-copyright-enforcement-plan/.

${ }^{13}$ Put simply, a business application is any process or program a business uses to run more efficiently. Business applications can range from industry-wide offered services to specialized tools specifically designed for a small business. Applications can include 1) internal or external developed systems, 2) customized third-party provided systems, and 3) processes that run on client computers or servers. Business Application Definition, TeCHNET.Microsoft.com, http://technet.microsoft.com/en-us/library/cc961268.aspx (last visited Nov. 7, 2012).

${ }^{14}$ Jonathan Strickland, How Cloud Computing Works, HowSTUFFWORKS, http://computer.howstuffworks.com/cloud-computing/cloud-computing2.htm (last visited Nov. 7, 2012) (discussing benefits of cloud computing).

${ }^{15}$ See generally, Christian Arno, The Advantages of Using Cloud Computing, Cloud ComPUTING Journal (Apr. 14, 2011), http://cloudcomputing.sys-con.com/node/1792026; Jerry Grisham, The Benefits of Cloud Computing, THESMALLBUSINESS.ORG, http://www.thesmallbusiness.org/software/benefits-of-cloud-computing.html (last visited
} 
associated with the development, use, and maintenance of the expanding network

correspondingly increase. The increasing costs associated with expanding networks stand as an obstacle for smaller companies to develop an extensive network. ${ }^{16}$ Resultantly, small business organizations are likely to fail in competition with bigger companies, which possess the means of affording the equipment and costs necessary to expand their business. ${ }^{17}$

Taking advantage of its infinite storage space and fast delivery, cloud computing has emerged as a desirable method for small and large businesses to efficiently run needed applications at low costs. ${ }^{18}$ Recognizing the medium's potential to lower costs and increase capabilities, independent filmmakers have turned to the cloud for the financing, production, and distribution of motion pictures. ${ }^{19}$ Editing software that is delivered over the cloud has opened doors to enhanced Computer Generated Image (CGI) capacity. ${ }^{20}$ Previously, the costs of distributing films had prevented independent filmmakers from reaching a larger market, thus reducing the possibility of earning recognition and funding for potential future projects. ${ }^{21}$ With cloud computing, filmmakers can turn to cloud providers over the Internet and pay a subscription for the production applications to be accessible anywhere and at any time, thus reducing the

Nov. 5, 2012); Bernard Golden, How to Explain Cloud Computing to Your CIO, CIO (Nov. 5, 2008), http://www.cio.com/article/print/459819.

${ }^{16}$ How Small Businesses Can Leverage Cloud Computing to Save Money, CloudTwEAKS (Sept. 4, 2012), http://www.cloudtweaks.com/2012/09/how-small-businesses-can-leverage-cloud-computing-to-save-money/ (detailing benefits of cloud computing to lower energy costs).

${ }^{17}$ Melinda Emerson, Could Your Small Business Benefit from Cloud Computing?, SMALLBIZLADY (July 24, 2012), http://succeedasyourownboss.com/07/2012/could-your-small-business-benefit-from-cloud-computing/ (discussing how previous capacities only available to larger businesses can now be used by small business owners).

${ }^{18}$ Edge Strategies, supra note 1. A Microsoft survey of small business owners found that $44 \%$ believe that cloud computing makes them more competitive. $53 \%$ of those polled believed the switch to cloud computing services would improve sales volume.

${ }^{19}$ Steele, supra note 2.

${ }^{20}$ Marketwire, MoPix Launches Rich Digital Distribution Platform for Independent Filmmakers, VIRTUALIZATION JOURNAL (Aug. 13, 2012), http://virtualization.sys-con.com/node/2329354.

${ }^{21}$ Steele, supra note 11. "The cost of marketing a film to a national audience has become so prohibitively expensive that domestic distributors, as a whole, have become an endangered species. The chances that a small, indie film will be acquired by a domestic distributor are slim to none." Id. 
barriers to production and distribution. Although cloud computing comes in numerous forms and can be either industry-wide or customer-specific, ${ }^{22}$ there are three primary models of delivery.

\section{A. Infrastructure as a Service}

Commonly referred to as the "base layer", Infrastructure as a Service ("IaaS") serves as the foundation for cloud computing. ${ }^{23}$ All infrastructure required by a business - including servers, routers, firewalls, data storage and utility, and other network equipment - is provided by the IaaS provider. For example, with Amazon Elastic Compute Cloud (Amazon EC2), clients pay either an hourly rate or a flat rate for using the server capacity. ${ }^{24}$ The customer is free to modify the amount of service that is provided. ${ }^{25}$

\section{B. Platform as a Service}

As an intermediate level between basic infrastructure and highly specialized software, Platform as a Service ("PaaS") is a variation in which the purchasing company uses a third-party web provider's infrastructure to create or upload its own materials that are in turn used to create individual applications or products. ${ }^{26}$ The provider will deliver the platform on the web, and in

\footnotetext{
${ }^{22}$ For a distinction between industry-wide "public clouds" and customer-specific "private clouds," see Kjel Hanson, Private vs. Public Cloud Computing, Cloud ComPuting Journal (Apr. 5, 2012), http://cloudcomputing.syscon.com/node/2230961.

${ }^{23}$ Simon Fidian \& Jeremy Allen, Harnessing the Power of Cloud Services, WAVECom Solutions, http://www.wavecomsolutions.com/index.php/news/51-2011-06-08-harnessing-cloud-computing (last visited Nov. 8, 2012).

${ }^{24}$ Amazon Elastic Cloud Compute (AMAZON EC2), AMAZON, http://aws.amazon.com/ec2/ (last visited Oct. 12, 2012).

${ }^{25}$ IBM offers flexible services, which customers can scale to their needs whenever they choose. IBM Infrastructure As A Service, IBM SMARTCLOUD ENTERPRISE, http://www-935.ibm.com/services/us/en/cloud-enterprise (last visited Nov. 7, 2012).

${ }^{26}$ IaaS, PaaS, SaaS (Explained, Compared), APPRENDA, http://apprenda.com/library/paas/iaas-paas-saas-explainedcompared/ (last visited Nov. 7, 2012).
} 
most cases, customers can work on the platform by using their own browsers. ${ }^{27}$ There is no need to download any software. This combination of simplicity and cost efficiency empowers small and mid-size companies, or even individual developers, to launch their own software services. ${ }^{28}$ Google App Engine and Bungee Connect are both examples of platform services. ${ }^{29}$ MoPix, a digital distribution start-up, announced in August 2012 that it was launching a Platform as a Service distribution site where users could upload videos that they had filmed. ${ }^{30}$ Following the upload, the users can use the MoPix platform to create their own content controls, similar to a DVD-menu. ${ }^{31}$ The application further allows for the direct distribution to iTunes, or Google Play. $^{32}$

\section{Software as a Service}

Software as a Service ("SaaS") is the most specialized form of cloud computing and consists of web based services, directly used by consumers. ${ }^{33}$ These packages are then used in specific divisions of a company, such as human resources. ${ }^{34}$ On the customer side, it means that up-front investments in servers or software licensing are unnecessary, and any additions to the software can be purchased on an "as-needed" basis. ${ }^{35}$ Providers benefit because they do not have

${ }^{27}$ What is PaaS?, INTERoUTE, http://www.interoute.com/vdc/what-is-paas (last visited Nov. 7, 2012).

${ }^{28}$ See Understanding the Cloud Computing Stack: SaaS, PaaS, IaaS, RACKSPACE SUPPORT (Sept. 12, 2012), http://www.rackspace.com/knowledge_center/whitepaper/understanding-the-cloud-computing-stack-saas-paas-iaas (discussing the characteristics of PaaS).

${ }^{29}$ Chris Keene, What Is Platform as a Service (PaaS)?, Cloud Zone (Mar. 29, 2009), http://cloud.dzone.com/articles/what-platform-service-paas.

${ }^{30}$ Marketwire, supra note 12.

${ }^{31} \mathrm{Id}$.

${ }^{32} I d$.

${ }^{33}$ Basant Narayan Singh, SaaS Introduction with Examples - Cloud Services Model, TECHNO-PULSE (Apr. 27, 2012), http://www.techno-pulse.com/2010/04/saas-introduction-example-cloud-service.html.

${ }^{34}$ SaaS Solutions for Human Resources (HR)/Workforce Management Organizations, SAVVIS (2012), http://www.savvis.com/en-us/info_center/documents/saas-us-saasforhr.pdf.

${ }^{35}$ Abe Sultan, SaaS 101: The Benefits, SAASBLOGS (May 2, 2007), http://www.saasblogs.com/business/saas-101the-benefits/. 
to send engineers to multiple locations to install and maintain software, nor do they have to face the logistical problems of rolling out a large-scale upgrade every few years. ${ }^{36}$ Salesforce, a SaaS provider, provides sales software for Burberry, NBC Universal, and ActiVision. ${ }^{37}$ Software delivered through a cloud for the purposes of production, such as the software hosted on the MoPix platform, are tools that filmmakers can rely upon without purchasing entire product packages. $^{38}$

\section{PART II: Cloud Computing's Benefit to Filmmakers}

Few industries are poised to take advantage of the potential benefits of cloud computing like the motion picture industry. The production of a film can involve multiple production shops and contractors working together on short-term projects. ${ }^{39}$ As producing a film is project-based, with the goal of creating a one-off product, there is no need to create a high-capacity IT infrastructure that can be reused. By creating their own cloud, or using an IaaS provider to increase storage and production capacity, large film studios have already begun to use cloud services to lower costs and increase capabilities. ${ }^{40}$ In 2011,20 percent of the computing work performed for DreamWorks Animation's Kung Fu Panda 2 was created in the cloud. ${ }^{41}$ Subsequently, DreamWorks collaborated with Cerelink(R) to render the animation for How to Train Your Dragon, a film that grossed over $\$ 250$ million dollars. ${ }^{42}$

\footnotetext{
${ }^{36} \mathrm{Id}$.

${ }^{37}$ List of Salesforce Customers, SALESFORCE (Apr. 16, 2012, 9:00 AM), http://www.salesforce.com/customers/.

${ }^{38}$ Marketwire, supra note 20.

${ }^{39}$ Barb Darrow, NAB: Cloud Computing is Ready for its Closeup, GIGAOM.COM (Apr. 16, 2012, 9:00 AM), http://gigaom.com/cloud/nab-cloud-computing-is-ready-for-its-closeup/.

${ }^{40}$ Id. (discussing popularity of Amazon's public cloud).

${ }^{41}$ Avgerakis, supra note 3.

${ }^{42}$ Cerelink (R) and DreamWorks Animation Use Cloud Computing to Render New 3D Feature How to Train Your Dragon, PR NEWSWIRE, http://finance.paidcontent.org/paidcontent/news/read/12665278/cerelink (last visited Oct. 14, 2012).
} 
While major film studios are using cloud computing as a means of increasing production capabilities, independent filmmakers are also taking advantage of the low costs involved. The use of IaaS and PaaS services to both improve the quality of the product and to lessen the difficulties of distributing finished films has resulted in the transformation of independent filmmakers that has been termed a "democratization of film."

Independent filmmakers have always faced budgetary constraints that restrict an independent film's capacity to reach an audience. ${ }^{44}$ The inability to shoot in exotic locations and the lack of large production soundstages contribute to stories of a smaller scope. ${ }^{45}$ Commercially successful action-adventure independent films are rare, as the budget necessary to create pyrotechnic effects or use high-quality CGI is often out-of-reach. ${ }^{46}$ Cloud computing has transformed independent filmmaking at the post-production level by increasing the number of stories available to be told. RenderMan CGI, an initiative created by Pixar, allows for independent filmmakers to upload a job and pay for its completion through Windows Azure, a PaaS. ${ }^{47}$ Iron Sky, an upcoming Finnish independent release, used RenderMan as well as some collaborative help to create special effects similar to a Hollywood-scale production. ${ }^{48}$ Approaching its release at multiple venues in the United States, director Timo Vuorensola, lauded the fact that high-quality effects were readily available to filmmakers everywhere. ${ }^{49}$

\footnotetext{
${ }^{43}$ Steele, supra note 2.

${ }^{44}$ Jeff Steele, Why Films Under \$2M Can't Catch a Break, HuFFIngTON Post, Apr. 19, 2010, http://www.huffingtonpost.com/jeff-steele/why-films-under-2m-cant-c_b_542383.html.

${ }^{45}$ See generally, Kevin L. Powers, 5 Elements to Picking a Good Location on an Independent Film, YAHOO VoICES (June 1, 2010), http://voices.yahoo.com/5-elements-picking-good-location-independent-6119810.html; Mark Anderson, Indies Blow Up Filmmaking With CGI, STUDIO360.oRG (June 22, 2012), http://www.studio360.org/2012/jun/22/indie-film-cgi/.

${ }_{46}^{46}$ Anderson, supra note 12.

${ }^{47} I d$.

${ }^{48}$ GreenButton and Pixar Bring Big Budget CGI to Indie Film Makers, GREENBUTTON, https://www.greenbutton.com/blog/index.php/2012/06/26/greenbutton-and-pixar-bring-big-budget-cgi-to-indie-filmmakers-2/ (last visited Nov. 17, 2012). 
In addition to the benefits of rendering images and CGI effects through platform as a service, IaaS providers have also allowed independent filmmakers to store their data in large capacities rather than relying on reels. ${ }^{50}$ Coupled with digital cameras, this also increases the ease in which footage can be uploaded into common storage spaces like DropBox and shared on the cloud. Using a digital camera and uploading the information to a storage center on an IaaS, or directly to editing software hosted on a PaaS, drastically reduces costs, and opens filmmaking to anyone with access to a digital camera.

Most notably, independent filmmakers benefit from the ability to distribute their films via the cloud. ${ }^{51}$ Cloud computing has given rise to different avenues for distribution that were previously limited by their prohibitive cost, and reduced and the necessity to find financing to overcome that cost. ${ }^{52}$ In addition to only a single digital copy being needed, the distribution over a PaaS eliminates the preliminary need for partnerships with financiers or distributors. ${ }^{53}$ On March 11 ${ }^{\text {th }}, 2012$, Girl Walks Into a Bar became the first feature-length motion picture that was released directly onto YouTube. ${ }^{54}$ After being uploaded, the film received 100,000 views in 24 hours. ${ }^{55}$ This film was distributed without a distribution agreement in place; however, the

\footnotetext{
${ }^{50}$ Venom, Another Dropbox Storage Increase - New Plans Include 500GB, TECHMAIDEN (July 10, 2012), http://www.techmaiden.com/another-dropbox-storage-increase-new-plans-included-upto-500gb/.

${ }^{51}$ Sean Landers, Independent Films in the Digital Age: A Triumph of Diversity over Scarcity, ARTICLEJOE.COM, http://www.articlejoe.com/Article/Independent-Films-in-the-Digital-Age--A-Triumph-of-Diversity-overScarcity/24294 (last visited Nov. 7, 2012).

52 Id.

${ }^{53} \mathrm{Id}$.

${ }^{54}$ First Feature Film Distributed Via Youtube, InDEPENDENT MEDIA MAGAZINE, http://www.indiemediamag.com/2011/movies/first-feature-film-distributed-via-youtube (last visited Oct. 18, 2012).

${ }^{55}$ Liz Shannon Miller, Will Girl Walks Into a Bar Lead Indie Films to the Web?, GIGAOM (Mar. 12, 2011, 1:26 PM), http://gigaom.com/video/girl-walks-into-a-bar-

youtube/?utm_source=feedburner\&utm_medium=feed\&utm_campaign=Feed\%3A+newteevee+\%28GigaOM\%3A+ Video\%29.
} 
potential for monetization in the future made an agreement more equally negotiable due to the success of the film, thereby leaving a valid distribution arrangement as an available option. ${ }^{56}$

As the costs of production, storage, and distribution decrease, a film with a relatively low viewership, such as Girl Walks Into a Bar, has the potential for a profit. ${ }^{57}$

This significantly opens a door for the smaller independent filmmakers. Filmmakers can create and distribute an entire film via the cloud at a low cost. A filmmaker who is using an IaaS service, like DropBox, for storing footage and then transferring it to a PaS service for the editing and the post-production work, reduces the costs associated with producing a film. More importantly, using the cloud for the distribution of that lower-cost film allows the filmmaker to potentially make substantial profit without pre-negotiating the success away in a distribution arrangement. However, as promising as cloud computing sounds for independent filmmakers, the usage of cloud computing as the medium for growth poses a significant risk. As cloud computing content is difficult to regulate, the providers of websites, such as YouTube, were faced with a serious challenge during the debates regarding the Stop Online Privacy Act. ${ }^{58}$ While SOPA is indeed dead, the individual provisions that regulated the sites that hosted usershared content forecast cloudy skies for those that would benefit most by the free distribution.

\section{PART III: SOPA, TPP, and the dangers to Cloud Computing and Filmmakers}

While multiple government parties have confirmed that SOPA is not going to return, the general thrust of the legislation still poses a threat to cloud computing as a medium. As a means of increasing the power of independent filmmakers via digital media, use of the cloud depends

\footnotetext{
${ }^{56} I d$.

${ }^{57}$ Landers, supra note 49.

${ }^{58}$ Josiah M. Hesse \& Patrick Rodgers, The problems with SOPA and its sweeping side effects, DENVER WESTWORD BLOGS (Jan. 25, 2012, 8:30 AM), http://blogs.westword.com/backbeat/2012/01/the_problems_with_the_stop_online_piracy_act.php.
} 
on the certainty that its growth will continue to offer benefits. Users of an IaaS provider, like DropBox, questioned this certainty when Mega Upload and MegaVideo, two file-sharing websites, were shut down for copyright infringement in January $2012 .{ }^{59}$ While there were copyright infringing parties who were arrested, many users noted that Mega Upload's auxiliary function as a form of IaaS storage was the main use for many subscribers. ${ }^{60}$ As the storage use of the cloud is important for digital filmmakers, the websites offering services with similar auxiliary functions, such as DropBox, were alarmed by the broad push towards shutting down infringing sites. That concern has been realized in the form of the negotiations surrounding the Trans-Pacific Trade Partnership. ${ }^{61}$ While SOPA is gone, the Trans-Pacific Trade Partnership (TPP) Agreement is being negotiated between the United States and Pacific nations, and the US parties with direct access to the negotiating table are some of the strongest one-time proponents of the SOPA legislation. ${ }^{62}$

In order to examine the danger posed by the TPP Agreement to the use of cloud computing, the problems with the SOPA legislation must be identified. While the negotiations are ongoing, it is troubling to see that language mirroring key provisions of the SOPA legislation is being included. ${ }^{63}$ Furthermore, the negotiations to the TPP Agreement are being criticized as lacking transparency, and providing too much access to parties most interested in the strict enforcement of copyright laws, namely those that championed SOPA. ${ }^{64}$ The TPP's negotiations

\footnotetext{
${ }^{59}$ Jeff Norman, SOPA, PIPA, and the Cloud: We Have "Mega” Issues, ClOUDTWEAKS.COM (Jan. 23, 2012), http://www.cloudtweaks.com/2012/01/sopa-pipa-and-the-cloud-we-have-mega-issues/.

${ }^{60}$ Megaupload, Megavideo Shutdown: Not All Users Broke the Law, INT'L BUS. TIMES (Jan. 23, 2012, 6:11 PM), http://www.ibtimes.com/megaupload-megavideo-shutdown-not-all-users-broke-law-399594.

${ }^{61}$ Dean Baker, The Pacific free trade deal that's anything but free, THE GUARDIAN (Aug. 27, 2012, 11:11 AM), http://www.guardian.co.uk/commentisfree/2012/aug/27/pacific-free-trade-deal.

${ }^{62} \mathrm{Id}$.

${ }^{63}$ Critics Concerned Trade Agreement Will Include SOPA Language, TECHCENTRAL.IE (Sept. 10, 2012), http://www.techcentral.ie/19809/critics-concerned-trade-agreement-will-include-sopa-language.

${ }^{64}$ Eric Stadius \& Elizabeth Briggs, The Trans-Pacific Partnership: Free Trade at What Costs?, COUNCIL ON HEMISPHERIC AFFAIRS (Aug. 20, 2012), http://www.coha.org/the-trans-pacific-partnership-free-trade-at-what-costs/.
} 
reflect the danger SOPA posed to cloud computing's growth as a medium for independent filmmaking.

There were two key provisions in the proposed SOPA legislation. The first, Section 102, granted certain rights to the Attorney General to combat "foreign infringing site[s]." 65 If a site, which was located abroad but directed at the United States, was committing criminal copyright violations, the Attorney General's Office could take action against the site and be awarded a temporary restraining order, a preliminary injunction or a permanent injunction against the operation of the site. ${ }^{66}$ The court order would then be served upon 1) Internet Service providers, 2) search engines, 3) payment providers, and 4) Internet advertising services (companies that facilitated the placement of ads on websites), which would then have been obligated to stop doing business with the foreign infringing site. ${ }^{67}$ If a provision such as this were to be included in the TPP Agreement, it would mean that a cloud platform provider would be required to prevent user access to the cloud while search engines, such as Google, would have to stop providing links to that site.

The second, and more problematic, aspect of SOPA was found in Section 103, labeled the "Market-Based System." 68 Under $§ 103$, the content-owners were given the right to take action against sites "dedicated to theft of U.S. property." 69 Content-owners were given the power to notify 1) payment providers and 2) Internet advertising servicers that they were providing services to a site "dedicated to theft of U.S. property."70 The receipt of this notice obligated such entities to cease providing services to the site in question within 5 days of

\footnotetext{
${ }^{65}$ Stop Online Piracy Act, H.R. 3261, 112th Cong. § 102(b)(1)(B) (2011) [hereinafter SOPA].

${ }^{66}$ SOPA $\S 102(b)(5)$.

${ }^{67} I d . \S 102(\mathrm{c})(2)$.

${ }^{68} \mathrm{Id} . \S 103$.

${ }^{69} I d . \S 103(\mathrm{c})(2)$.

${ }^{70} I d . \S 103(\mathrm{~b})(4)(\mathrm{A})(\mathrm{iii})$.
} 
receiving the notice unless they received an effective "counternotification" from the site. ${ }^{71}$ If the payment providers or advertising servicers did not comply, or if the site in question issued a counter-notification, then the content-owner could take court action against the site itself. ${ }^{72}$ Pursuant to this action, the payment providers or Internet advertisers could have been forced to stop doing business with the site. ${ }^{73}$

The first problem for cloud computing providers, and the independent filmmakers that rely on the cloud, is that SOPA (and potentially the TPP Agreement) itself did not limit $§ 103$ to foreign-based sites. Rather, it targeted those that were "US-directed" sites. ${ }^{74}$ Any site providing any cloud service to filmmakers could fall under this classification. The nature of the "direction" was left similarly vague. The language of $\S 103(\mathrm{a})(1)$ indicated that a site would be considered dedicated to theft if it "has only limited purpose or use other than . . offering goods or services in a manner that engages in, enables, or facilitates" illegal acts, including copyright infringement. ${ }^{75}$ Under this standard, sites such as YouTube, Daily Motion, and Vimeo, could have been targeted as they have no other purpose than a portal in which users can upload and watch videos. If a user uploaded copyright infringing material, any qualifying plaintiff under $\S$ 103(a)(2) could have brought an action. As cloud computing allows data to be uploaded, accessed, and edited anywhere and by anyone, there is no way to determine whether there is a "US-directed" site or service provider. Any future attempts to regulate based on the "direction" of the site will continue to create headaches for users and providers.

Furthermore, under $\S 103(\mathrm{a})(1)(\mathrm{B})(\mathrm{ii})$, any service provider that took deliberate action to avoid confirming a high probability that their site was being used to carry out copyright-

\footnotetext{
${ }^{71}$ SOPA $\S 103(b)(5)$.

${ }^{72}$ Id. $\S 103(\mathrm{c})$.

${ }^{73} I d . \S 103(\mathrm{~d})(2)(\mathrm{A})-(\mathrm{B})$.

${ }^{74}$ Id. $\$ 103(\mathrm{a})(1)(\mathrm{A})$.

${ }^{75}$ Id. $\S 103(\mathrm{a})(1)(\mathrm{B})$.
} 
infringing acts would be considered to be dedicated within the meaning of $\S 103$ (a). ${ }^{76}$ Service providers under SOPA could have been forced to aggressively police content uploads in order to avoid falling under that definition. As the financial incentive behind protecting copyright remains, the regulation of those sites that may contain copyright-infringing material by selfregulation remains troubling for those sites that host material.

Included among the leaked provisions of the TTP Agreement is article 16.3, which provides for "ISP obligations to block access to websites that allegedly infringe or facilitate copyright infringement," and opens the door for efforts "to force intermediaries to disclose the identities of their customers to IP rights holders on an allegation of copyright infringement.",77 Filmmakers using the sites for the storage of production materials and the distribution of films would now face the possibility that smaller cloud providers, such as an SaaS provider offering editing software over a PaaS cloud, would simply stop offering the service because they could not afford the compliance time and cost or disclose confidential client information when a copyright holder merely alleges a violation. Similarly, if an independent filmmaker relied entirely on a service, like DropBox, to store the production as it took shape, then simply shutting down a website could result in months of lost work. Users complained that when the government shut down Megaupload, most of their content was simply lost. ${ }^{78}$ The TPP Agreement carries with it the same concern for those filmmakers who are storing their production work in the cloud.

Finally, even those sites that have come to represent important distribution vehicles for filmmakers would face considerable uncertainty as a result of the industry's focus on advertisers

\footnotetext{
${ }^{76}$ SOPA, H.R. 3261, 112 th Cong. § 103(a)(1)(B)(ii).

${ }^{77}$ Carolina Rossini \& Kurt Opsahl, TPP Creates Legal Incentives For ISPs to Police the Internet. What Is At Risk? Your Rights, ElECTRONIC FRONTIER FOUND. (Aug. 24, 2012), www.eff.org/deeplinks/2012/08/tpp-createsliabilities-isps-and-put-your-rights-risk.

${ }^{78}$ Norman, supra note 59.
} 
and payment providers. While YouTube has the capacity to restrict user uploads, pressure placed on YouTube advertising revenue pursuant to $\S 103(b)(5)$ would have created situations in which the major distribution vehicles for many independent filmmakers could no longer function. Although the leaked information is limited, the concern that one-time proponents of SOPA are driving the negotiations creates an uncertainty that the medium will likely be under the same restrictions that were present under SOPA. ${ }^{79}$

\section{CONCLUSION}

The ongoing negotiations and the lack of transparency surrounding these negotiations are creating real concerns for the world of cloud computing and its application to the growth of independent filmmaking. Because of this, while groups in the entertainment and Internet industries meet to discuss potential arrangements for self-regulation, independent filmmakers cannot wholly embrace the cloud-computing medium as a means of enhancing their production and easing their distribution burden due to the looming shadow of the return of SOPA-style legislation in the guise of a free trade agreement. As a result, users of cloud computing face an uncertain future: filled with potential, but tempered by the cloudy skies that just passed and darken the horizon.

\footnotetext{
${ }^{79}$ Critics Concerned Trade Agreement Will Include SOPA Language, supra note 63.
} 